\title{
La política hacia las inversiones extranjeras del gobierno de Néstor Kirchner: tras los rasgos de un populismo atemperado'
}

\author{
José Marcelino Fernández Alonso \\ Doutorando em Relações Internacionais (Universidad Nacional de Rosario) \\ Rosario, Santa Fe, Argentina \\ josefernandezalonso@hotmail.com
}

\begin{abstract}
Resumen El colapso de Argentina a fines de 2001 supuso el fracaso del proceso de reestructuración económica encauzado bajo los lineamientos del relato neoliberal. En ruptura discursiva con las políticas identificadas como responsables de aquella debacle, el gobierno de Néstor Kirchner (2003-2007) se propuso desandar el camino de liberalización trazado conforme los imperativos del "Consenso de Washington". Los elementos de cambio y/o ruptura tuvieron en la política respecto a las inversiones extranjeras uno de sus exponentes más alusivos. A partir de desarrollos conceptuales propios de la sociología política, el presente trabajo analiza la política respecto a las inversiones extranjeras durante la administración Kirchner. Tras la consideración del juego pendular de integración/exclusión de las inversiones extranjeras, identifica en la política bajo estudio rasgos de populismo atemperado.
\end{abstract}

Palabras claves: República argentina, Néstor Kirchner, populismo atemperado, política, inversiones extranjeras.

\section{Introducción}

T a Asunción de Néstor Kirchner a la presidencia de Argentina en Lmayo de 2003 estuvo enmarcada por profusas tensiones e imprevisiones. A los complejos desafíos derivados del colapso político-económico de fines de 2001 se sumaron las contrariedades en términos de legitimidad suscitadas tras la renuncia del ex presidente y nuevamente candidato Carlos Menem, que participó en la segunda vuelta de la elección presidencial. Así las cosas, Kirchner, un gobernador de exigua gravitación hasta entonces en la arena de la política nacional debió encarar un horizonte signado por la potencialidad de una crisis de gobernabilidad. Con el respaldo primigenio del $22 \%$ de los votos obtenidos en el primer turno electoral y carente del liderazgo en su partido de referencia, el Justicialista -jaqueado aún por los estertores del colapso político-institucional-, Kirchner inauguró su gobierno en circunstancias inéditas para la historia democrática argentina reciente. Sólo el apoyo coyuntural del presidente provisional saliente Eduardo Duhalde y la decisión del flamante mandatario de mantener en su gabinete a ministros de aquél -el de Economía, Roberto Lavagna, en particular- parecieron atemperar parte de las inquietudes al sugerir cierta continuidad de una administración que en los meses inmediatos

1. El autor agradece los valiosos comentarios de los evaluadores anónimos. 
anteriores había conseguido revertir el proceso de retracción económica acarreado en torno a la crisis del régimen de convertibilidad.

No obstante la multiplicidad de los retos, lo cierto es que pocos meses debieron transcurrir para que Kirchner sellara su impronta en el direccionamiento del escenario político argentino. En palabras de Iazzetta (2005, p. 39),

la debilidad de origen que intentó ponerle Menem con su deserción, fue revertida por Kirchner en un muy breve tiempo, favorecido por un estilo hiperactivo de gestión, por una enérgica recuperación de la iniciativa política y por desplegar un contacto cara a cara con la población que le permitió establecer un vínculo directo con la sociedad, sorteando la mediación de su partido.

Con un discurso acentuado en la ruptura con el pasado inminente y apoyado en no pocas ocasiones de maniobras de sobreactuación, el presidente se propuso como el gestor de un proceso de renovación, de refundación de la política nacional. Emprendió, a tales efectos, "una estrategia de legitimación que sobredimensionó la protesta social expresada en el "que se vayan todos" de diciembre de 2001. Donde la fragmentación partidaria se planteaba, Kirchner denunció a la corporación política, simulando arriesgar una guerra contra ella" (Ollier, 2005, p. 11). Crítico de las políticas cursadas por las administraciones democráticas respecto a los delitos de lesa humanidad cometidos durante el denominado proceso de reorganización nacional y en reivindicación de la generación militante sesgada en aquellos años, apuntó el presidente la urgencia de dar fin a un período marcado por la impunidad. Avanzó, en consecuencia, en la renovación de la cúpula de las Fuerzas Armadas y la derogación de las denominadas leyes de Obediencia Debida y de Punto Final. De forma concomitante, impulsó la modificación de la composición de la Corte Suprema de Justicia de la Nación, cuyos fallos y omisiones habían ratificado la impunidad y los malogros del período democrático.

Fiel a la lógica de refundación, Kirchner puso en discusión las resultantes de las políticas de liberalización y desregulación, iniciadas -no fortuitamente- en el marco de la dictadura y profundizadas en la década precedente bajo las administraciones de Menem y de Fernando de la Rúa. Conforme su lectura, las políticas implementadas bajo auspicios del proyecto neoliberal habían conducido al debilitamiento del tejido social al tiempo de socavar las atribuciones soberanas en el manejo de la economía nacional. El colapso de 2001, manifestado en el deterioro crónico de los indicadores sociales y en la declaración de cesación de pagos más importante en términos absolutos en la historia económica global, no había sido sino el corolario del fracaso de las políticas de reformas neoliberales. Como consecuencia, debía de propiciarse una nueva configuración en la relación entre el Estado y el mercado. En función de tal premisa, el gobierno instrumentó una miríada de acciones que procurarían reposicionar el rol del Estado como direccionador del mercado. En esa inteligencia, se impelieron sendas iniciativas para la reestatización y/o renacionalización de empresas y sectores afectados por el proceso de reestructuración económica auspiciada por el neoliberalismo (espacio radioeléctrico, empresas de servicios postales, de distribución de aguas y servicios sanitarios, de energía, entre otras).

Dicho eso, es de señalar que en paralelo a la consolidación del poder presidencial y al despeje consecuente de las inquietudes primigenias en materia de legitimidad y gobernabilidad del país en general, comenzó a emerger un prolífico debate respecto a la caracterización del nuevo gobierno.

Diversas fueron las categorías o expresiones que avivaron la polémica sobre el encuadre teórico-conceptual del mismo: "populista", "progresista", "de izquierda", "de centroizquierda", entre los más ensayados. Polémica, por cierto, harto complejizada al considerarse la raigambre de Kirchner en el peronismo, fenómeno siempre reticente a los ensayos de definición conceptual (Chavez, 2007, p. 64). La dificultad del encuadre del kirchnerismo quedó por cierto evidenciada en la cada vez más voluminosa literatura sobre las modificaciones inminentes en la región latinoamericana, atravesada incrementalmente por gobiernos también críticos de los respectivos pasados socio-políticos y objetores, en lo capital, de las estrategias de liberalización y desregulación estructuradas durante la hegemonía del mentado "Consenso de Washington". Más aún, la contrariedad para la categorización del gobierno de Kirchner se hizo del todo explícita en aquellos estudios que pretendieron -y pretenden- analizar el denominado "giro hacia la izquierda" en clave dicotómica, esto es, diferenciando a los nuevos gobiernos y movimientos en el poder entre aquellos pertenecientes a una izquierda "populista y peligrosa" (ejemplificada por tales lecturas en los casos de Venezuela, Bolivia y Ecuador) y aquellos otros propios de una izquierda "liberal y moderadamente progresista" (ilustrada generalmente con el Chile de la Concertación) (Plot y Semán, 2007, p. 356-357).

Dos son los criterios que concurren para dar cuenta de las dificultades para la categorización del gobierno kirchnerista; de seguro extensibles a las experiencias latinoamericanas de hogaño. Por un lado, y próximo al ámbito de lo metodológico, es de vincularse la complejidad del debate con la heterogeneidad y cercanía temporal de las políticas de revisión y/o ruptura por los gobiernos encauzadas. Conviene señalar al respec- 
to que, lejos de constituir un todo unidireccional y compacto, se tratan de experiencias atravesadas -en licencia del concepto gramsciano de crisis- por "aquello viejo que no termina de morir y aquello nuevo que no termina de nacer". Signadas por la inmediatez y la recursividad, las políticas en cuestión reportan vastas dificultades para ser comprehendidas de manera estable bajo un significante determinado. Por otro lado, y lindante ya al plano epistemológico, las dificultades a propósito de la categorización se vinculan al uso acrítico, indiscriminado, de los conceptos en consideración. El uso precipitado, sumario de los términos, remite en parte a la sempiterna crítica sobre falta de precisión conceptual en el ámbito de las ciencias sociales, pero también a las dificultades y/o escaso interés de no pocos analistas de tomar distancia de la carga normativa de tales términos en su uso cotidiano, intuitivo.

Advertido de las contrariedades de la empresa de categorización y sin ánimo de poner clausura al debate suscitado a su alrededor, el trabajo propone analizar al gobierno de Kirchner en términos de un "populismo atemperado". En ese sentido, el estudio sostiene como hipótesis central que el gobierno de Néstor Kirchner (2003-2007) constituyó un mecanismo de articulación de solidaridades políticas basado en el uso extremo del juego pendular de la exclusión/inclusión de un "otro", inherente a todo proyecto de construcción identitario. Para el contraste de tal hipótesis, el trabajo escruta la lógica de exclusión/inclusión discursiva del gobierno de Kirchner respecto a un alterno, a un heterogéneo particular: la inversión extranjera -el inversor extranjero, por extensión- en tanto epítome del orden neoliberal contra el cual erigió sus fronteras identitarias. De modo concreto, indaga la lógica de inclusión/exclusión a los inversores extranjeros en tanto mecanismo de construcción identitaria en dos instancias de la política económica exterior: (a) el proceso de reestructuración de la deuda soberana y (b) la controversia con Uruguay a propósito de la instalación de las plantas de producción de pasta de celulosa.

Tras esa introducción, el trabajo avanza sobre el andamiaje teórico-conceptual que habilita el presente análisis. Seguidamente, da cuenta de la lógica de exclusión/inclusión de los inversores extranjeros en las dos dimensiones recién comentadas. Por último, y conforme las convenciones de rigor, el trabajo consigna reflexiones finales a modo de conclusión.

\section{El recorrido obligado por el sendero de un concepto polisémico}

Advierte Aboy Carlés (2002, p. 9), no sin dejo de ironía, sobre el trillado recorrido seguido por buena parte de los estudios sobre populismo. Constitutivos de un "subgénero menor de la literatura académica", esos trabajos comienzan, en lo general, por denunciar la ambigüedad del concepto; tras ello, se dedican a criticar los usos y las conceptualizaciones "que con distinto grado de felicidad tienen vigencia”; para finalmente abocarse a desarrollar y establecer una definición propia que deje en evidencia la "torpeza" de colegas precedentes.

No innova ese trabajo, en sus inicios, la trayectoria en cuestión. Si bien lejano al propósito de esbozar aquella definición final superadora, empieza por repasar algunos de los múltiples usos del significante "populismo" a fin de echar luz sobre el abordaje teórico-conceptual sobre el que se erige el presente estudio.

Una primera línea de aproximación -la de mayor uso y disfusión, por cierto- entiende al populismo como un conjunto o set de políticas positivas encaminadas a proteger y promover el mercado doméstico. En ese marco, el término encuentra en las políticas de los gobiernos latinoamericanos asumidos tras la crisis de los treinta su más acabada manifestación: "un Estado interventor y asistencialista, con control de los servicios públicos; propiedad y control estatal en diversas esferas de la producción y comercialización, proteccionismo comercial, utilización política del gasto público y redistribución de los ingresos" (Aboy Carlés, 2002, p. 10).

Como una derivación sofisticada de ese uso, el concepto de populismo es referenciado para dar cuenta de la "particular relación entre el Estado y actores sociales característica de dichas políticas" (Aboy Carlés, 2002, p. 10). En términos generales, puede indicarse que ésta fue, en buena medida, la perspectiva de los primeros estudiosos -clásicos, en la actualidad- del fenómeno del populismo en América Latina (Germani, Di Tella, Weffort, entre los más destacados). Sin minusvalorar los matices entre los autores en mención, se advierte que se trató de un uso o abordaje atravesado por la idea de un complejo de político signado por la crisis propia de la transición desde una sociedad tradicional a una moderna. En ese marco, el populismo tenía por rasgos constitutivos

una amplia movilización social; la integración de las clases populares principalmente pero no exclusivamente urbanas en un esquema de articulación política multiclasista; la promoción de una mayor diferenciación económica capitalista con énfasis industrializador, impulsada desde un estado intervensionista dentro de una estrategia de economía mixta y no alineamiento internacional; de resonancias ideológicas nacionalistas; con una conducción fuertemente personalizada. (Vilas, 2004, p. 136) 
La articulación del significante "populismo" como un set de políticas concretas es reservada por Vilas en su crítica a aquellos análisis que durante la década del noventa advertían sobre la existencia de un neopopulismo latinoamericano, otro de los tantos usos del concepto para dar cuenta de realidades nacionales de imperantes en aquella época en las que un líder apelaba al respaldo de los sectores populares en el afán de ejecutar políticas opuestas a aquellas implementadas en el auge de los "populismos clásicos" latinoamericanos. Contrario a la "jibarización" a la que se había sometido el término en la mencionada década, Vilas subraya, consecuentemente, la imperiosidad de entender al populismo como un concepto constreñido "a una etapa particular del capitalismo periférico" que, como tal, no puede de trasladarse a coyunturas harto diferenciadas. Conforme expone, el populismo referencia "dimensiones e ingredientes políticos, ideológicos, estructurales, estilos de liderazgo, etc., que posiblemente no fueron originales en sí mismos o aisladamente considerados, pero cuya peculiar combinación dio origen a nuevos rasgos y definió la caracterización específica del conjunto" (Vilas, 2004, p. 136).

Un último uso del término es finalmente propuesto desde el campo de la sociología política, donde numerosos autores, munidos de los derarrollos conceptuales de las teorías del discurso y de la identidad, entienden al populismo no ya como un conjunto determinado de políticas concretas, sino más bien como un modo específico de articular identidades -solidaridades- políticas. En ese caso, el populismo se constituye entonces como una lógica política mediante la cual una pluralidad de demandas insatisfechas de una parte significativa de esa sociedad política comienzan a plasmarse en símbolos comunes, que resultan luego interpelados en el discurso de un líder rupturista con el sistema vigente (Laclau, 2006). En marco de tal lógica, una parte (plebs) reclama ser concebida como un todo (populus) legítimo. En función de ello, abre y cierra de modo irresuble fronteras frente a un otro, frente a un "externo", el cual habilita la constitución identitaria propia.

De las múltiples definiciones discutidas en el uso de ese último abordaje, el trabajo toma nota de la formulada por Aboy Carlés (2005, p. 27), quien considera al populismo como un "mecanismo específico de gestión de la tensión entre la afirmación de la propia identidad diferencial y la pretensión de una representación hegemónica de la sociedad". Esa especificidad del mecanismo está dada por la forma extrema en la que el adversario es incluido y excluido en el campo de representación. Especial importancia tiene esa última nota, debido a ser el uso extremo de esa tensión el que particulariza al populismo de todas las demás empresas de construcción identitaria. A tales efectos, no debe de descuidarse que "toda identidad políti- ca está sometida a esa tensión entre la afirmación de su carácter diferencial específico y la pretensión de ampliar el espacio de su representación" (Aboy Carlés, 2005, p. 13). El populismo, en consecuencia, se refiere a un fenómeno y remite, en última instancia, a una escala de grados, reconociendo en uno de sus extremos su tipo ideal.

Claves para la definición de populismo aquí consideradas resultan los términos de hegemonismo y fundacionalismo. Siguiendo lo planteado por el precitado autor, entiéndese por el primero "un tipo particular de articulación hegemónica que pretende la clausura de cualquier espacio de diferencias al interior de la comunidad". El fundacionalismo, por su parte, da cuenta del ensayo de constituir abruptas fronteras temporales entre "una situación pasada pero aún cercana o amenazante que es demonizada y considerada oprobiosa, y un tiempo posterior venturoso que aparece como la contracara vis à vis de ese pasado que se pretende dejar atrás" (Aboy Carlés, 2005, p. 14).

En esa lógica -a veces simultánea, a veces alternativa- de inclusión y exclusión del adversario, las fronteras populistas resultan siempre contingentes. En su análisis del trabajo de Aboy Carlés, Barros (2006, p. 148) comenta:

la exclusión/inclusión del adversario hace a la dinámica del proceso articulatorio que implica una frontera siempre inestable y en desplazamiento constante. En esa movilidad, los adversarios a veces quedan dentro y a veces quedan fuera de la esfera de las solidaridades del populismo. Esto es así, ninguna frontera identitaria es estática, sino que se va reestructurando de forma constante.

Si bien en buena medida reminiscentes de las políticas positivas articuladas en el período de los populismos clásicos latinoamericanos (el (re)posicionamiento del rol del Estado en la estructuración y el funcionamiento de vastos sectores y mercados, el (re)direccionamiento del gasto social, la (re)instauración de herramientas de políticas comerciales de corte proteccionista, o hasta la misma (re)articulación de un diálogo pretendidamente directo entre el gobierno y la sociedad, esto es, sin intermediación precisa de los partidos), el presente trabajo adopta para su marco teórico el último de los usos considerados. Esto último permite indagar, no sin cierta polémica, los rasgos distintivos del gobierno kirchnerista desde un enfoque más comprehensivo. En ese sentido, se advierte que el recurso a los desarrollos últimos de la sociología política coadyuvan avanzar en el análisis de un fenómeno complejo el cual excede los parámetros de los enfoques clásicos.

Se adelantó en la introducción del trabajo la identificación en el gobierno de Kirchner de rasgos 
propios de un populismo "atemperado". Es momento de aclarar el porqué de la adjetivación. Nuevamente, el estudio se asiste de lo formulado por Aboy Carlés. Según analiza, el pluralismo político en el período democrático institucionalizado "ha mermado la impronta hegemonista que latió en el populismo clásico. En este sentido, el populismo constituye una experiencia del pasado" (Aboy Carlés, 2005, p. 25). Así las cosas, se observa que tras el proceso de democratización los proyectos de constitución identitaria no pretenden ya la clausura de toda diferencia al interior de las fronteras de esa sociedad política. No ocurrió lo mismo, por cierto, con el rasgo fundacionalista, una constante en los períodos presidenciales sucedidos tras la instauración democrática; a excepción del gobierno de Fernando de la Rúa (1999-2001). A tales efectos, puede bien añadirse que, salvo aquella excepción, todos los gobiernos argentinos asumidos desde 1983 procuraron presentarse como los hacedores de una nueva etapa, de una nueva política, de una nueva Argentina, en última instancia, que pondría fin a aquel pasado identificado como ominoso, causa de los reveses y contrariedades de cada uno de esos "presentes".

Es momento de articular los conceptos revisados con el problema de investigación arriba formulado. Como se indicó, Kirchner encaró su mandato con un discurso de ruptura con el pasado inmediato. Se inauguraría con su gobierno una nueva etapa en la que no habría espacio para la impunidad a los crímenes de lesa humanidad ni la indiferencia al crecimiento de la inequidad social. Sería, en breve, el conductor de la salida del "infierno" concretado en estallido de la crisis del relato neoliberal, pero también de aquel otro precipitado el 24 de marzo de 1976. En ese afán fundacional, Kirchner buscó marcar diferencias con los responsables y protagonistas de aquel pasado que había llevado al colapso argentino. Las fracturas temporales de su proyecto hegemónico y refundacional se presentaban respecto a dos momentos que, aunque diferenciados, se reportaban comunicados, en primer término, por la impunidad de los delitos de la dictadura militar, y, en segundo término, por la continuidad de los programas de reestructuración económica liberal.

En ese contexto de configuración identitaria, los inversores extranjeros -los tenedores de bonos, las empresas privatizadas- asomaron como uno de los actores responsables/beneficiarios del tránsito de Argentina al debacle. Junto a ellos, y siguiendo a Barros (2006, p. 159), "los economistas neoliberales, las compañías que se beneficiaron del neoliberalismo, los organismos multilaterales de crédito". Frente a esos actores debían de constituirse las fronteras del proceso político en ciernes. No eran, desde luego, los únicos. Piénsese aquí las fracturas respecto a la cúpula militar y a la "corporación política" consideradas en las líneas introductorias.
En ese marco, el actor "inversor extranjero", cual promotor -y protagonista- de un proyecto (neoliberal) diseñado y ejecutado a expensas del empobrecimiento del país, se constituyó discursivamente en el adversario, en un elemento heterogéneo que hizo posible la constitución misma de su identidad, de su "cadena equivalencial", en términos de Laclau. Constitución, por cierto, que no resulta nunca acabada. Es que, tal como expone el precitado autor, lo heterogéneo, lo exterior, habilita la clausura de la estructura, pero haciéndola al mismo imposible. En tal sentido advierte: "la construcción de cualquier "interior" sólo va a ser un intento parcial de dominar un "exterior" que siempre va a exceder esos intentos" (Laclau, 2005, p. 186).

Presentado el marco teórico-conceptual, se propone a continuación indagar los rasgos populistas de la administración kirchnerista en dos contextos en particular.

\section{El proceso de renegociación de la deuda en cesación de pagos}

El mecanismo de inclusión/exclusión de la inversión extranjera tuvo en el proceso de reestructuración de la deuda soberana un palmario asomo. Se adelantó líneas arriba que los tenedores de los bonos en default aparecieron en el discurso de Kirchner como un "alterno", como operadores del mundo globalizado que habían redituado con la República Argentina desde el comienzo del proceso de endeudamiento en la década del setenta.

En paralelo a la deslegitimación, al expulsar allende las fronteras de la identidad en construcción, se reconocía la necesidad de acordar con tales actores la salida del default. Argentina, cual país deficitario en recursos para impulsar su desarrollo, necesitaba reinsertarse en el sistema financiero internacional, aunque eso en condiciones diferentes a las adoptadas cuando del predominio del modelo neoliberal. Exclusión e integración constituyeron, simultánea y alternativamente, empresas de una misma operación.

Sin ser propósito del presente trabajo analizar en detalle la reestructuración de la deuda soberana, se consideran en lo siguiente los principales momentos del proceso a luz de la lógica populista de exclusión/ integración.

En el discurso inaugural de su mandato, Néstor Kirchner puso en manifiesto los términos en los que operaría el mecanismo de integración. Tras anunciar una inminente apertura de negociaciones con los tenedores de títulos en cesación de pagos, apuntó que esas gestiones debían conciliar el nivel de endeuda- 
miento con las condiciones de pago efectivas del país: "Los acreedores" -sostuvo- "tienen que entender que sólo podrán cobrar si a la Argentina le va bien".

Medio año debió trascurrir para que esa apertura -cual momento de integración- se concretara; tiempo requerido para alcanzar un acuerdo a largo plazo con el Fondo Monetario Internacional, que enmarcara el proceso de reestructuración de la deuda en default.

Presentada en setiembre de 2003, la denominada "propuesta de Dubai" fundó sus lineamientos en la necesidad de compatibilizar el nivel de endeudamiento argentino con el concepto rector de "sustentabilidad". Bajo esos argumentos, los funcionarios del gobierno kirchnerista anunciaron la quita del $75 \%$ del valor nominal sobre la deuda de capital en cesación de pagos, lo cual implicaba una reducción del endeudamiento en casi U\$S 65.000 millones, en breve la mayor quita en términos absolutos en la historia reciente del sistema financiero internacional. Por otra parte, apuntaron que Argentina no reconocería el pago de los vencimientos de interés adeudados desde el anuncio del default. Por último, y sin adentrar en especificaciones técnicas, los negociadores del país aludieron que los bonos a ofrecerse extenderían considerablemente los plazos de pago al tiempo de reducir los intereses. Las condiciones de la propuesta no tardaron en ser rechazadas. Para los bonistas, la propuesta resultaba inaceptable en la medida que se trataba de una merma harto superior a la trazada por Rusia y Ecuador, los antecedentes inmediatos en procesos de reestructuración de deuda soberana. Más inadmisible aún les resultaba la negativa del gobierno argentino a reconocer los intereses vencidos desde diciembre de 2001. Por último, cuestionaban la unilateralidad de la propuesta y la negativa del gobierno a reconocer a las asociaciones de bonistas como interlocutores en la reestructuración. Ese último reparo, vale acentuar, reviste cabal interés a los fines del trabajo. En tal sentido, el rechazo del gobierno a negociar con tales asociaciones no constituía sino una expresión del momento de exclusión.

El repudio de los tenedores a la oferta y las presiones de los gobiernos de los países desarrollados e instituciones financieras internacionales obligaron al gobierno a instrumentar una nueva estrategia para la integración. Así las cosas, el $1^{\circ}$ de junio de 2004 el Ministerio de Economía dio a conocer una nueva oferta, conocida como la "Propuesta de Buenos Aires". Entre las novedades de la oferta, las más notorias fueron: la decisión de reconocer los intereses vencidos desde diciembre de 2001 y la institución de las "unidades ligadas al crecimiento", un "premio" anual en efectivo basado en el desempeño económico del país.

Como mecanismo para explicitar las condiciones para la integración/exclusión tras la nueva propuesta, el gobierno "sugirió que se mostraría conforme con una aceptación del 50\% en adelante y advirtió que ésta era la última oferta y que quien no adhiera se quedaría con 'papeles sin valor"” (Damill, Frenkel y Rapetti, 2005, p. 224). Lo propio puede apuntarse respecto a la sanción de una ley mediante la cual se impedía al Poder Ejecutivo introducir nuevas modificaciones a la mentada Propuesta de Buenos Aires.

Tras múltiples reveses en la apertura y desarrollo de la operación del canje, el gobierno anunció en marzo de 2005 que la aceptación a su propuesta de reestructuración había alcanzado el 76,15\%. Se trató del momento decisivo de la integración. Con su aceptación, los bonistas habrían de (re)incorporarse a un proyecto en el que el articularse al mundo no se hacía a costa del "hambre y la sed de los argentinos", en palabras de Kirchner.

Aunque en apariencia cercano al dato anecdótico, es de destacar que el acto de presentación de los resultados del canje reportó la concurrencia de representantes de diversos sectores de la escena político-económica nacional. Entre ellos, el ex presidente Raúl Alfonsín (1983-1989), con quien el gobierno había marcado distancias en virtud de la pretensión fundacionalista de la política Kirchnerista de Derechos Humanos y de castigo a los delitos de lesa humanidad, en particular. Con la presencia de diversos referentes socio-políticos, el gobierno buscó exponer que los resultados de la restructuración de la deuda, problemática que había atravesado el período democrático, estaban respaldados por un todo.

Integrados los bonistas en una reestructuración atenta a las necesidades del pueblo, sólo quedaría la frontera, la fractura con aquellos que habían rechazado la oferta de canje, los denominados holdouts. Sería en ellos donde recaería en adelante la identificación del alterno, del externo.

\section{El conflicto por la instalación de las plantas de pasta de celulosa}

La segunda instancia en la que se escruta la exclusión/integración discursiva de las inversiones extranjeras (los inversores extranjeros) resulta, tal vez, la más polémica, en tanto las fronteras de identidad no se restringen al contexto político nacional, sino que son trasladadas a un espacio mayor, esto es, el escenario regional.

En ese punto, las inversiones vendrían a hacerse de los recursos naturales y de la calidad de vida de los pueblos en desarrollo. Con ese actuar, las empresas multinacionales contaminantes irrumpirían en un espacio identitario -llámese, "Países "Hermanos" del Río de la Plata", "Mercosur", "Latinoamérica" o, 
sencillamente, "Sur"- conformado por países en desarrollo copartícipes de una misma historia y un destino común. El planteo pone en discusión la condición de aquellos Estados que, urgidos de recursos para motorizar su desarrollo, promueven la radicación de inversiones extranjeras perniciosas al medioambiente, desafiando consiguientemente los lazos de solidaridad de una comunidad política ampliada.

El juego de tensión entre la integración y la ruptura quedó expuesta en la alocución de Kirchner en la mesa de trabajo matinal de la IV Cumbre Unión Europea - América Latina y Caribe del 12 de mayo de 2006:

Nuestros países desean recibir inversiones y presentan rentables oportunidades, en energía, transportes e infraestructura, y aún en sectores sensibles, ubicándose allí un enorme campo de colaboración. Pero no queremos que lleven allí actividades proscriptas aquí, para mejorar el beneficio de los accionistas creando la ilusión de un producto supuestamente más barato, pero de elevado costo de contaminación ambiental, deterioro de la salud y reducción de las expectativas de vida.

Diversos fueron los acontecimientos que marcaron los momentos de exclusión del discurso del gobierno Kirchnerista sobre el particular. A los comentados cuestionamientos a las inversiones extranjeras contaminantes y a sus países de origen, vino a sumarse la interposición de la controversia contra Uruguay en instancias de la Corte Internacional de Justicia (CIJ). Las acciones de exclusión quedaron manifiestas del mismo modo en los reclamos directos a la Corporación Financiera Internacional, organismo perteneciente al Grupo Banco Mundial proveedor de parte significativa del financiamiento para la radicación de los emprendimientos.

El momento de integración, por su parte, es el más controvertido, puesto que supone la aceptación dentro de la(s) frontera(s) a las inversiones objeto de la controversia y al daño ecológico de éstas derivado. En marco del conflicto, la integración estuvo dada tanto en la propuesta del gobierno de Kirchner relativa del monitoreo ecológico conjunto como así también en las negociaciones cursadas con la firma española ENCE para su relocalización. El análisis del momento de integración potencia su polémica al considerarse que la proclama ecologista perdería la pretendida entidad de máxima rectora del discurso kirchnerista. En ese marco, el momento de integración estaría vehiculizado por el relajamiento y/o la laxitud de las exigencias a inversores extranjeros en otros sectores y regiones del país para la instalación y funcionamiento de nuevos -y viejos- emprendimientos. Inscríbanse, a modo ilustrativo, las múltiples denuncias de conta- minación contra las mineras en la región cordillerana o contra la decena de plantas productoras de celulosa ubicadas dentro del territorio económico nacional.

Hasta aquí el apartado centró su atención en la gestión de la tensión entre la integración y la exclusión de las inversiones extranjeras en marco de una frontera identitaria "ampliada". No es, desde luego, el único abordaje posible. El manejo de la tensión puede analizarse en términos de construcción y transformación de identidad nacional. En ese caso, las inversiones extranjeras contaminantes -y los Estados limítrofes que las aceptan, por extensión- se constituyen en el adversario que atenta contra la defensa medioambiental, identificada cual "causa nacional".

Tal línea de análisis fue en cierta medida abordada en el debate respecto al diseño y a la ejecución de la Política Exterior en tiempos de Kirchner. En tal marco, y en relación explícita con el problema de las pasteras, Escudé advirtió que la decisión del gobierno nacional de asimilar las demandas de los ciudadanos de Gualeguaychú e impulsar en lo consiguiente la confrontación con Uruguay obedeció al estrecho margen de maniobra de un sistema político signado por la crisis de gobernabilidad "latente pero permanente". En sus palabras,

en la Argentina post-De la Rúa importa menos convencer al mundo que calmar a aquellos cuya protesta puede contribuir a desestabilizar al gobierno. Por eso en la querella uruguaya por el corte de rutas, se alega que estas acciones populares pero ilegales y sediciosas no fueron más que el ejercicio del legítimo derecho a la protesta. El Estado confiere carácter legal a la violación de sus propias leyes. Así se tranquiliza a los revoltosos a costa de agudizar el deterioro de las instituciones. [...] Este es el infierno que nos supimos conseguir: el sacrificio de la política exterior a la política interna y el sacrificio del largo plazo del interés nacional al corto plazo de la estabilidad de un gobierno. (Escudé, 2006, p. 4)

Desde una perspectiva opuesta, Palermo (2006, p. 3) afirmó que el accionar del gobierno argentino -y del presidente Kirchner, en particular- respondió al "aprovechamiento casi de manual, probablemente un cálculo equivocado, orientado a suscitar aprobación doméstica". Conforme Palermo (2006, p. 2), "Kirchner no es un presidente arrinconado por la crisis, bajo amenazas latentes de "golpes de estados civiles" (al decir de Escudé) ni nada por el estilo, sino un presidente que dispone de elevados grados de libertad para escoger y dar forma a su agenda".

Más allá de la polémica, subyace en ambas posiciones y en la literatura sobre la cuestión en particular la idea de que el impulso al reclamo de los ciudadanos de Gualeguaychú (en tanto demandas populares 
insatisfechas) sirvió como mecanismo generador de recursos de poder. En el abordaje de esa cuestión, el gobierno de Kirchner acenturía precisamente su carácter fundacionalista. En el discurso de los funcionarios y del propio presidente, era la vez primera en la que un gobierno argentino hacía propias las inquietudes de los ciudadanos en materia ecológica.

\section{Reflexiones finales}

El colapso de Argentina a fines de 2001 supuso el fracaso del proceso de reestructuración económica encauzado bajo los lineamientos del relato neoliberal. Identificado durante buena parte de la década del noventa como el modelo de estabilización y desregulación por agentes referenciales de la escena económica global, el país había precipitado su ensayo de reforma a una crisis económico-institucional signada por el deterioro crónico de sus indicadores sociales y la declaración de cesación de pagos de deuda soberana más importante -en términos absolutos- en la historia contemporánea del sistema financiero internacional.

En ruptura discursiva con las políticas identificadas como responsables de aquella debacle, el gobierno de Kirchner se propuso desandar el camino de liberalización trazado conforme los imperativos del denominado "Consenso de Washington". Los elementos de cambio y ruptura tuvieron en la política respecto a las inversiones extranjeras -a los inversores extranjeros, por extensión- uno de sus exponentes más alusivos. En ese contexto, comenzaron a desvirtuarse las condiciones y/o concesiones estructuradas en los tiempos de reforma a fin de promover la articulación del país con los flujos internacionales de inversión. De modo progresivo, conceptos tales como "soberanía económica", "renacionalización”, "re-estatización" -marginados, silenciados bajo la hegemonía del discurso neoliberal- comenzaron a gravitar nuevamente en la política argentina.

La caracterización del gobierno por Kirchner suscitó vasta polémica. "Populista", "progresista", "de izquierda", "de centroizquierda" fueron sólo algunas de las profusas categorías abordadas por los analistas para adjetivar las políticas encauzadas tras la crisis de 2001. Caracterización por cierto complejizada al considerarse el sustrato "peronista" de los gobiernos en cuestión (Chavez, 2007, p. 64). Tal debate, conforme se advirtió en el principiar del trabajo, no se circunscribió a la realidad argentina, sino que se correspondió con las encendidas polémicas en torno al análisis de las experiencias de revisión de las reformas neoliberales en la región latinoamericana en la actualidad.

Sin ánimo de dar clausura a tales discusiones, el estudio postuló la existencia en el gobierno de Kirch- ner de rasgos inherentes a un populismo atemperado. Eso fue así en tanto hizo uso en extremo del juego pendular de integración y exclusión de la alteridad constitutiva del marco identitario propio. Con tal premisa de partida, el estudio indagó el mecanismo de inclusión/exclusión respecto a las inversiones extranjeras, a los inversores extranjeros, como actores nodales del proyecto o el sistema contra el cual erigía su constitución identitaria. Dos fueron los momentos o situaciones en los que el mentado mecanismo fue indagado: el proceso de reestructuración de la deuda soberana en cesación de pagos y la controversia con Uruguay a raíz de la instalación de las productoras de pasta de celulosa.

Identificados como uno de los grandes responsables/beneficiarios del pasado neoliberal, los tenedores de bonos fueron entendidos como la alteridad, la heterogeneidad frente a la cual debía de constituirse las fronteras del demos a representar. En su discurso rupturista, Kirchner buscó delimitar los espacios entre aquellos arraigados a un pasado marcado por la desigualdad y otros orientados a un horizonte de desarrollo redistributivo y de recuperación de lo nacional. Así, resultan oportunas, en ese punto, las palabras de Barros (2006, p. 159) respecto a la práctica populista del gobierno de Kirchner:

es en los sin voz que aparece el espectro del pueblo que ronda y asedia a las voces identificadas con el pasado, los economistas neoliberales, las compañías que se benefician del neoliberalismo, los organismos multilaterales de crédito, etc. En esta disputa entre los sin voz y los grandes beneficiados de la década del noventa, es donde aparece la figura de un discurso que no es neutral.

En paralelo a la exclusión, pudieron reportarse ensayos de integración. En ese punto marco, se inscribieron los llamados a compatibilizar el beneficio de los inversores con las necesidades del pueblo, salido apenas del "infierno". Se reconocía así la imposibilidad del cierre de la estructura. Fueron las propuestas de reestructuración donde el gobierno expuso las condiciones para integrar a la alteridad: empresas e inversores recuperarían rentabilidad y capital, pero sin ello significara poner en juego la estabilidad.

La lógica de inclusión/exclusión de las inversiones extranjeras en el caso de las productoras de celulosa refirió a la construcción de una frontera identitaria que excede al plano de lo estrictamente nacional. La alteridad estuvo está identificada en aquellas firmas extranjeras contaminadoras, las cuales, aprovechándose de las necesidades de recursos de los países en desarrollo, tensionan los lazos de solidaridad política entre actores con una historia y un destino compartido. 
Tras caracterizar de extremo al uso dado por la administración Kirchner al juego de exclusión/ inclusión en relación con las inversiones extranjeras, conviene ensayar una respuesta al porqué de tal lógica de hacer y significar la política. A tales efectos, puede apuntarse que se trató de una respuesta estratégica para (re)configurar poder en un escenario aún jaquedo por los estertores del colapso de 2001. El Kirchnerismo, en definitiva, no devendría sino en un ensayo de resolución comprehensivo para aquel contexto de crisis en el que las demandas de buena parte de la sociedad no encontraban satisfacción mediante los canales institucionalizados (los partidos políticos tradicionales, entre ellos).

En referencia a la especificidad del populismo, Aboy Carlés recurre a la alegoría de Penélope, dedicada de exclusivo al tejer y al destejer la mortaja de
Laertes. La política del gobierno de Kirchner respecto a las inversiones extranjeras bien se correspondió con ella. Articulado en el fundacionalismo y hegemonismo (atenuado) de base, el gobierno configuró y reconfiguró pendularmente las fronteras respecto a la inversión externa. Tal pendular, capital para la constitución identitaria en la escena politica doméstica durante el período, no resultó desde luego gratuita. A tales efectos, se advierte finalmente que el mentado pendular fue recurrentemente controvertido por las denuncias y/o cuestionamientos de actores (tanto nacionales como internacionales) sobre las deficiencias de la República Argentina en materia de "seguridad jurídica", expresión que, aunque siempre polisémica, marcó -y marca- los costos del mentado juego en términos de estabilidad.

\section{Referencias}

ABOY CARLÉS, Gerardo. Repensando el populismo. Revista Política y Gestión, n. 4, p. 9-34, 2002.

. Populismo y democracia en la Argentina contemporánea. Entre el hegemonismo y la refundación. Estudios Sociales, n. 28, p. 125-149, 2005.

BARROS, Sebastián. Espectralidad e inestabilidad institucional. Acerca de la ruptura populista. Estudios Sociales, n. 30, p. 145-162, 2006.

CHAVEZ, Daniel. Hacer o no hacer: los gobiernos progresistas de Argentina, Brasil y Uruguay frente a las privatizaciones. Revista Nueva Sociedad, n. 207, p. 63-79, 2007.

DAMILL, Mario; FRENKEL, Roberto; RAPETTI, Martín. La deuda argentina: historia, default y reestructuración. Desarrollo Económico, v. 45, n. 178, p. 187-233, 2005.

ESCUDÉ, Carlos. El conflicto de las papeleras y la muerte de la política exterior. Boletín ISIAE, año 9, n. 40, p. 3-4, 2006. IAZZETTA, Osvaldo. El gobierno de Kirchner y los desafíos democráticos pendientes. Temas y debates, n. 10, año 9, p. 35-56, 2005.
LACLAU, Ernesto. La razón populista. Buenos Aires: Fondo de Cultura Económica, 2005.

. La deriva populista y la centroizquierda latinoamericana. Nueva Sociedad, n. 205, p. 56-61, sep./oct. 2006. OLLIER, María Matilde. Liderazgo presidencial y jefatura partidaria: entre la confrontación y el pacto (20032005). Temas y debates, n. 10, año 9, p. 7-34, 2005.

PALERMO, Vicente. Path dependence o grados de libertad? La política exterior argentina vivita y coleando. Librevista, Montevideo, 1 ago. 2006. Disponible en: <http:// www.escenariosalternativos.org/home.asp $>$. Acceso en: enero de 2010.

PLOT, Martín; SEMÁN, Ernesto. Neither/Nor: Mapping Latin America's Response to Neoliberalism and Neoconservatism. Constellations, v. 14, n. 3, p. 355-372, 2007.

VILAS, Carlos M. ¿Populismos reciclados o neoliberalismo a secas? El mito del "neopopulismo" latinoamericano. Revista de Sociologia e Política, n. 22, p. 135-151, 2004. 


\title{
A política para os investimentos estrangeiros do governo de Néstor Kirchner: em busca das características de um populismo atenuado
}

\section{Resumo}

O colapso da Argentina, no final de 2001, marcou o fracasso do processo de reestruturação econômica, canalizado sob as orientações da narrativa neoliberal. Em uma ruptura discursiva com as políticas identificadas como responsáveis por esse desastre, o governo de Néstor Kirchner (2003-2007) tentou refazer o caminho de liberalização traçado de acordo com os imperativos do "Consenso de Washington”. As alterações e/ou rupturas na política, em relação ao investimento estrangeiro, são exemplos alusivos deste processo. Baseado nos conceitos da sociologia política, este trabalho analisa a política em relação ao investimento estrangeiro durante o governo Kirchner. Por meio da análise de um jogo de integração/exclusão, o artigo identifica na política estudada características de um populismo atenuado.

Palavras-chave: República argentina, Néstor Kirchner, populismo atenuado, política, investimentos estrangeiros.

\section{The policy towards foreign investment during Nestor Kirchner's administration: post populism-tempered features}

\begin{abstract}
The collapse of Argentina in 2001 marked the failure of the economic restructuring process channeled under the guidelines of neoliberal narrative. With a critical discourse towards the policies identified as responsible for that debacle, the government of Néstor Kirchner (2003-2007) tried to retrace the path imposed during the "Washington Consensus" era. The changes and/or ruptures in the policy towards foreign investment were allusive examples of this process. Based on concepts of political sociology, the article analyzes the policy towards foreign investment during the Kirchner administration. Through the consideration of an integration/exclusion game, the article identifies in the policy under study features of "tempered populism".
\end{abstract}

Key words: Argentine republic, Néstor Kirchner, tempered populism, policy, foreign investments.

Data de recebimento do artigo: 18/3/2010

Data de aprovação do artigo: 15/6/2010 